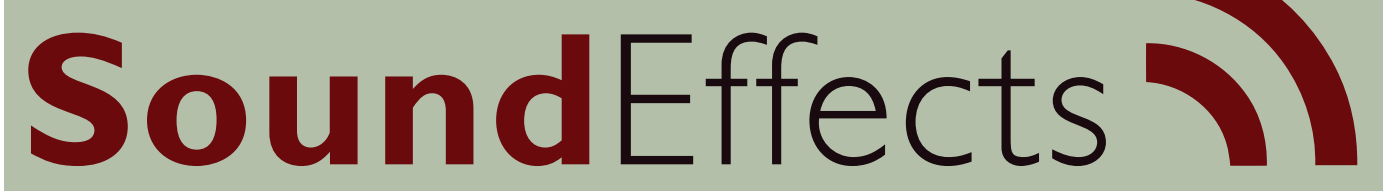

An Interdisciplinary Journal of Sound and Sound Experience

Nicolai Jørgensgaard Graakjær

\title{
Sounding out the logo shot
}

\author{
Nicolai Jørgensgaard Graakjæer \\ Professor with Specific Responsibilities \\ Department of Communication and Psychology \\ Aallborg University \\ nicolaig@hum.aau.dk
}




\begin{abstract}
This article focuses on how sound in combination with visuals (i.e. 'branding by') may possibly affect the signifying potentials (i.e. 'branding effect') of products and corporate brands (i.e. 'branding of') during logo shots in television commercials (i.e. 'branding through'). This particular focus adds both to the understanding of sound in television commercials and to the understanding of sound brands.

The article firstly presents a typology of sounds. Secondly, this typology is applied to an analysis of a case to illustrate how a textual analysis of sound and its audiovisual setting can offer relevant and necessary insights into processes of signification during a logo shot. Thirdly, the case is compared with 251 other cases from a larger sample of commercials. The analysis of the sample indicates the prevalence of sound brands and moreover it allows for further developing and nuancing of the presented sound typology.
\end{abstract}

\title{
Introduction
}

Logos are predominant features of television commercials, and there is practically no television commercial without a logo. Typically, often toward the end of the commercial, the logo will appear prominently during one to five seconds. The logo may appear either 1) alone, 2) in combination with a slogan and brand name sometimes integral to the logo or 3 ) as part of a pack shot, i.e., a shot presenting a particular product. These are three types of what I shall refer to as logo shots.

In this article, I will examine how sound accompanies the logo shot. As the logo is a pivotal part of a company's brand identity - there is practically no company without a logo - the examination is hence a contribution to the study of sound branding. As I shall illustrate below, not all logo shots include a sound brand. However, if a commercial includes a sound brand, it will expectedly appear during the logo shot.

Sound branding - i.e., the strategic use of sound for purposes of branding seems to have become increasingly widespread. Businesses of all kinds - e.g., big or small, private or public, national or international - are increasingly aware of the potentials of sound branding. Correspondingly, a growing number of producers of sound branding have emerged as have literature on various aspects of sound branding. Perhaps not too surprisingly, producers of sound branding have provided a significant portion of this literature characterized by company-promoting cases, records of sales, how-to-do-sections for practitioners, and declarations of sound brand format's alleged ability to affect listeners (e.g., Jackson 2003, Treasure 2007, Bronner \& Hirt 2009, Groves 2011, and Lucensky 2011). However, peer-reviewed research literature on sound branding has increased as well. Although this research is rather fragmented in terms of, e.g., research aim and methodology, the following 
four dimensions may perhaps serve as a general introduction to the perspectives included (see Graakjær \& Bonde 2013 for specific examples and an overview of the literature):

- 'Branding of ... '. This dimension concerns the object of sound branding, e.g., a corporation, a commercial setting or a particular product.

. 'Branding by .... This dimension concerns the type and dimension of sound in question - e.g., speech, music, musical genre - as well as the possible interaction between sound and non-auditory elements, e.g., visuals and scents.

- 'Branding through .... This dimension concerns the mediating setting of the sound, e.g., a website, a store or a telephone waiting line.

- 'Branding effect .... This dimension concerns the possible consequence that sound branding may have on, e.g., memory, attitudes or money and time spend.

In light of these dimensions, the present research is characterized by a focus on how sound in combination with the visuals (i.e., 'branding by') may possibly effect the signifying potentials (i.e., 'branding effect') of products and corporate brands (i.e., 'branding of') during logo shots in television commercials (i.e., 'branding through'). This particular focus adds generally to the understanding of sound in television commercials and specifically to the understanding of sound brands. So far, only little research (even if we include university dissertations) exists on, e.g., corporate sound brands, and the existing research tend to focus on the (effects of the) corporate sound brand itself, rather than on the audiovisual setting of the sound brand (e.g., Jackson 2006, Riggins 2007, Venkataraman 2007, Palghat 2009, Anzenbacher 2012, Bonde \& Bang 2012).

This article is hence based on the conviction that 1 ) insufficient scholarly attention has been focused on the audiovisual setting of sound in commercials during logo shots from a text analytical perspective and that 2) textual analysis of sound and its audiovisual setting offers relevant and necessary insights into processes of signification during logo shots. For example, to fully understand and explain the effects of corporate sound brands, it is necessary to include an analysis of the characteristics of sounds and their combination with visual expressions. Consequently, I will provide an examination of the ways in which sound combine with its co-texts - i.e., "... that portion of a text which (more or less immediately) surrounds it" (Mey 1993, p. 184) - in the audiovisual setting of the logo shot. The article will be guided by the following questions: Which sounds appear during the logo shot? How do the sounds relate to each other and to the visual setting? How do the sounds assist in presenting the logo and brand? In answering these questions, I aim to contribute to the understanding of (a particular aspect of) sound branding relevant to both 
analytics and producers. The examination is focused on the syntax and semantics rather than the pragmatics (Morris 1946) of sounds and their audiovisual setting, and the approach is inspired by text analytical theory on popular music signification (e.g., Tagg \& Clarida 2003), as well as previous research on television commercials and the distribution of address and sounds herein (e.g., Stigel 2001, Graakjær 2009).

Inspired by Schafer's suggestion to sound analytics, that: “... some system or systems of generic classification will have to be devised" (Schafer 1977, p. 9), I will firstly present a typology of sounds. A typology helps "to discover the significant features of the soundscape" (ibid.) and it can be used to indicate possible tendencies of the use of sound in larger samples of soundscapes. Secondly, I will apply this typology on a case to illustrate how a textual analysis of sound and its audiovisual setting can offer relevant and necessary insights into processes of signification during a logo shot. The case - i.e., the logo shot from a commercial for Fakta (a Danish supermarket chain) - has been chosen, because it seems to epitomize features of sound branding in commercials while being highly illustrative of the presented typology of sounds. Thirdly, I will compare the case of Fakta with other cases from a larger sample of commercials. Whereas the Fakta commercial has been chosen partially because of its expected exceptionality - i.e., presenting a case of sound branding the sample has been chosen with the aim to be able to indicate to what extend the Fakta commercial is actually exceptional while possibly including more usual and 'ordinary' cases as well. Expectedly, the sample thus allows for further developing and nuancing of the sound typology and its specific types of sounds.

The sample used in the present study consists of 252 unique television commercials broadcasted on the Danish TV channel TV 2 for the first time during the first two weeks of April 2012. The sample includes both nationally and internationally produced commercials, and the sample is arguably representative of the commercials broadcasted on TV 2. The purpose of the quantitative analysis is to indicate possible tendencies in a sample. This is a perspective lacking in most contributions on sound (branding) in commercials (see Allan 2008 and Graakjær 2009 for rare exceptions), and there is hence little knowledge about the actual prevalence of, e.g., sound brands. However, due to the relatively small number of commercials analyzed, proper statistical analysis will not be effectuated. The quantification is based on categories, which, to a considerable degree, are subjective. This is evident throughout the study, e.g., from the delineating of different types of sound to the delimiting of sound brands. Reliability is substantiated by the intention of analyzing all commercials in a similar way and in addition by elucidating the method of analysis (as much as space permits). 


\section{A typology of sounds}

I will now shortly present a typology of sounds. The typology is developed with the purpose of discovering the significant features of the soundscapes at hand, i.e., the sounds of logo shots during television commercials and the sound's audiovisual setting. Since the typology is inspired by the sample (see the case and sample analysis below), it does not pretend to be universally applicable to sounds of other genres and types of soundscapes. Theoretically, the typology is largely informed by classifications of sound in Leeuwen (1999) and Traux (2001), and it consists of a tripartite classification including speech, music, and object sounds. Hereby, the typology differs from other available typologies that does not, for example, highlight the importance of music as a particular type of sound, e.g., the classification of: "natural, animal, technical, and human" sounds in Augoyard \& Torgue (2006: 5). Whereas most readers will expectedly be familiar with the concepts of music and speech (see, e.g., Leeuwen 2001 and Graakjær 2009 for definitions), the concept of object sound needs further introduction.

'Object sounds' is used here as a residual category for the sounds which are neither speech nor music. Occasionally, the concept 'sound effects' is used to identify similar types of sound. I have chosen 'object sounds', though, to indicate, that the interest here is on the text and not the production of the text. Thus, from the perspective of production, most, if not all, the sample's sounds are 'sound effects' in the sense that audio technology has been used to fine tune and produce specific 'effects' out of not only the sound of objects but also the sounds of speech and music. Specifically, I define object sounds as those non-musicalized sounds that are presented during the text as deriving from (the motion of) psychical objects acknowledged from outside the universe of the commercial. For example, a 'swoosh'-sound (see below) represents the sound of wind resistance following from the sudden motion of an object of considerable size and weight. Also, the tooting sound of a car horn presents an object sound as long as it is not musicalized, i.e., presented as a harmonic, melodic and/or rhythmic expression that conforms to current norms of musical expressions - the latter is arguably illustrated in the sample: a commercial for Bilhuset Bornholm includes two separate toots, which produces a melodic interval of a descending third.

As I will illustrate below, not all logo shots include all three types of sound, and some logo shots are even devoid of sound. For example, in a commercial for Skoda, the logo shot presents the logo in full screen at the end with no accompanying sound (in fact, this commercial is the only one in the sample to include a logo shot with no accompanying sound, see below). In contrasting the preceding sound-full part of the commercial, the absence of sound here seems to function as an attention grabber. Arguably, the prominence of sound in contemporary commercials in general, 
Table 1. Outline of a commercial for Fakta

\begin{tabular}{|c|c|c|c|c|c|}
\hline $\begin{array}{l}\text { Time } \\
\text { (sec.) }\end{array}$ & $0-2$ & $2-12$ & $12-15$ & $15-17$ & $17-19$ \\
\hline \multirow{2}{*}{ Section } & \multicolumn{3}{|c|}{ Announcement } & \multicolumn{2}{|c|}{ Logo shot } \\
\hline & $\begin{array}{c}\text {...of an } \\
\text { event }\end{array}$ & $\begin{array}{l}\text {...of products } \\
\text { for sale }\end{array}$ & ...of an app & Construction & Confirmation \\
\hline Visuals & $\begin{array}{l}\text { A banner - } \\
\text { indicating } \\
\text { the event: } \\
\text { SHOP } \\
\text { AMOK - 'ar- } \\
\text { rives' from } \\
\text { the periph- } \\
\text { ery of the } \\
\text { screen and } \\
\text { is 'fastened' } \\
\text { on a red } \\
\text { background }\end{array}$ & $\begin{array}{l}\text { A number of } \\
\text { products are } \\
\text { seen 'arriving' } \\
\text { and presented } \\
\text { via pack-shots } \\
\text { on a red back- } \\
\text { ground. Prizes } \\
\text { are shown } \\
\text { animated as the } \\
\text { voice-over men- } \\
\text { tions them }\end{array}$ & $\begin{array}{l}\text { A hand is } \\
\text { seen in } \\
\text { close-up } \\
\text { presenting } \\
\text { a mobile } \\
\text { phone show- } \\
\text { ing the ban- } \\
\text { ner "SHOP } \\
\text { AMOK" as } \\
\text { well as some } \\
\text { of the prod- } \\
\text { ucts on sale }\end{array}$ & \begin{tabular}{|} 
Firstly, the brand \\
name is present- \\
ed via a flipping \\
entry. Secondly, \\
a badge pre- \\
senting opening \\
hours is 'arriving' \\
in the upper right \\
corner. Thirdly, \\
the slogan is \\
presented word \\
by word beneath \\
the brand name \\
and in synch with \\
the voice-over. \\
\end{tabular} & $\begin{array}{l}\text { The red } \\
\text { background } \\
\text { is in a fast } \\
\text { movement } \\
\text { perforated } \\
\text { right beneath } \\
\text { - as a kind of } \\
\text { underscore } \\
\text { of - the } \\
\text { words 'sund } \\
\text { fornuft' }\end{array}$ \\
\hline $\begin{array}{l}\text { Voice- } \\
\text { over } \\
\text { (in } \\
\text { Danish) }\end{array}$ & $\begin{array}{c}\text { Shop amok } \\
\text { i din lokale } \\
\text { discount } \\
\text { butik. }\end{array}$ & $\begin{array}{l}\text { På søndag, hvor } \\
\text { næsten alle } \\
\text { Fakta butikker } \\
\text { holder åben får } \\
\text { du en dansk } \\
\text { agurk til kun fem } \\
\text { kroner, Cocio } \\
\text { chokolademælk } \\
\text { til kun syv } \\
\text { femoghalvfems, } \\
\text { eller Neutral } \\
\text { vaskemiddel til } \\
\text { kun toogtyve } \\
\text { kroner }\end{array}$ & $\begin{array}{l}\text { Med Faktas } \\
\text { app har du } \\
\text { altid den } \\
\text { aktuelle avis } \\
\text { ved hånden. } \\
\text { Discount i... }\end{array}$ & $\begin{array}{l}\text { Fakta. Det' sund } \\
\text { fornuft }\end{array}$ & \\
\hline Music & & & & & $\begin{array}{l}\text { A jingle of } \\
\text { four notes }\end{array}$ \\
\hline $\begin{array}{l}\text { Object } \\
\text { sound }\end{array}$ & $\begin{array}{l}\text { A sound of } \\
\text { a 'bang' is } \\
\text { synchro- } \\
\text { nized with } \\
\text { the 'fasten- } \\
\text { ing' }\end{array}$ & $\begin{array}{l}\text { Object sounds } \\
\text { ('swoosh', } \\
\text { 'blop') appears } \\
\text { in synch with } \\
\text { the 'arrival' of } \\
\text { products, and } \\
\text { 'munch'-sound } \\
\text { accompanies } \\
\text { the showing of } \\
\text { cucumbers }\end{array}$ & $\begin{array}{l}\text { A 'buzz- } \\
\text { ing' sound } \\
\text { appears in } \\
\text { synch with } \\
\text { the pres- } \\
\text { entation of } \\
\text { the mobile } \\
\text { phone }\end{array}$ & $\begin{array}{l}\text { 'Swoosh'-sound } \\
\text { appears in synch } \\
\text { with the flip of } \\
\text { the brand name. } \\
\text { A 'blop' ac- } \\
\text { companies the } \\
\text { 'arrival' of the } \\
\text { badge }\end{array}$ & $\begin{array}{l}\text { A sound of } \\
\text { a swing- } \\
\text { ing sword } \\
\text { ('craasch') } \\
\text { appears in } \\
\text { synch with } \\
\text { the under- } \\
\text { scoring }\end{array}$ \\
\hline
\end{tabular}


and during logo shots in particular, may help to further fuel this function. Actually, perhaps as an indication of this function, empirical research has indicated how logo presentations without sound can outperform logo presentations with sound when it comes to recipient's brand recall (Venkataraman, 2007). However, as stated above, in the following I will focus on the appearances of sounds from a text analytical perspective beginning by an analysis of the case of Fakta.

\section{A case: Fakta}

Table 1 presents a rough outline of the commercial for Fakta. As illustrated, the logo shot appears during the concluding four seconds of the commercial, and it succeeds a course of announcements.

The visual style of the commercial is simple and stable. All shots are marked by a red background and presented from the same perspective. The first main section of the commercial, see 'Announcement' in table 1, includes a tripartite presentation of current company offers - i.e., an event, some products for sale, and an app - while the logo shot includes the logo and slogan, representing more durable features of the company. During the announcement, a female voice-over is auditorily foregrounded. The voice-over appears throughout at a high volume with pauses less than a second between sentences while object sounds occasionally accompanies the visual effects. The second main section of the commercial, see 'Logo shot' in table 1 , is characterized by one shot and there is no change in content during its appearance. However, the sequential construction of the content of the logo shot as well as a clear shift from the foregrounded voice-over to a foregrounded jingle presents a kind of sub sectioning of the logo shot (illustrated by dashed line in table 1).

The logo shot thus includes the three types of sound identified in the above typology: speech in the form of a voice-over, music in the form of a jingle, and object sounds (see more below). Syntactically, the sounds are measured in terms of both their mutual relationship and their relationship with the visual dimensions of the logo shot. As to their mutual relationship, the voice-over and jingle are successive, whereas the object sounds are concurrent with both the voice-over and the jingle. As regards the relationship to the visual co-texts, both the voice-over and the object sounds appear synchronized to visual elements, while the jingle concludes the commercial during no visual movements, apart from the short perforation underscoring of sund fornuft. In the following I will briefly examine in further detail what characterizes each of the three types of sound in the Fakta commercial.

Apart from being gendered, there is not anything distinctive about the voice. For example, the person performing the voice-over is anonymous. Moreover, the voice presents a standard Danish with a somewhat enthusiastic prosody, i.e., it appears a bit rushed and it accentuates specific words in a curving intonation hence resembling most other voice-overs in the sample (see below). Semantically, the subject 
and the references of the voice-over are continuously presented on the screen. The voice duets the visual presentation of the brand name and slogan, and the verbal features are hereby highlighted at the expense of the opening hours presented by the badge. Generally, the dominant function of the voice-over is to help construct and establish the presentation of the brand name and slogan.

The object sounds all correspond to specific visual motions. The animation of the brand name, the 'arrival' of the badge, and the perforation underscoring of sund fornuft can all be heard, i.e., 'swoosh', 'blop' and 'craasch', respectively. While the 'blop' ensures, that the 'arrival' of the badge with opening hours can be heard even if not mentioned during the voice-over, the 'swoosh' and 'craasch' further accentuates the visually presented brand name and slogan (for an empirical indication of a similar effect see Vroom 2000). Analogous to the sound quality of the voice-over, there is nothing distinct about the object sounds of the commercial. If anything, they may appear somewhat unsophisticated or 'cheap' compared to more refined and resonating timbres occasionally encountered in other commercials that might bear a resemblance to a style typical of television station promos or film trailers (Høier 2010). However, an unsophisticated style of object sounds is not emblematic of Fakta, as quite similar sounds and functions can be found in numerous commercials across the sample. Moreover, while the object sounds help highlight the brand name and slogan, the object sounds are not characteristic or indexical of the products and service of Fakta. For example, Fakta does not sell (s)words, and 'swoosh'- and 'blop'-sounds are neither keynote sounds, sound signals nor soundmarks (Schafer 1977) of the in store soundscape of Fakta.

When the jingle appears, the sequential construction of the logo shot is visually completed. Only the perforation underscore appears as a novel visual event, although it merely seems to accentuate what is already there (the words sund for$n u f t)$. As the voice-over has concluded, the jingle signals the end of the commercial as a kind of episode marker (Tagg \& Clarida 2003: 99ff). Moreover, if the logo, i.e., the brand name and the accompanying slogan, functions as a visual corporate brand signature, the jingle functions as an auditory brand signature and a confirming exclamation mark to finally conclude the logo construction process.

The jingle is quite unassuming. It is small-scaled (four notes with a narrow melodic range of a perfect fifth), short-lasting (less than two seconds), sparsely arranged (an unaccompanied classical guitar) and presenting a simple melody line (small intervals and uncomplicated rhythm) in a simple scale (major pentatonic). Even though the jingle is not in detailed synch with particular visual movements, the musical style of the jingle seem to match the simple visual stylistic features of the brand name and the slogan, i.e., few and clear colours and artless font. Also, the jingle seem to mirror the metric foot of the slogan as the jingle presents a third epitrite - or a spondee followed by a iamb - equivalent to the pronunciation of the 
slogan: Det' sund fornuft. Generally, the relative simple jingle appears to support the brand image of Fakta representing discount, common sense and a focus on facts and prices rather than, e.g., specific lifestyles.

Whereas neither the voice-over nor the object sound is emblematic to Fakta, the jingle arguably is. Even though similar musical expression can be found in the sample (see more below) there is no other commercial that includes this particular jingle. The jingle, thus, presents the sound brand of Fakta, and it functions alongside the visual brand (logo) and verbal brand (slogan) to represent the brand of Fakta. To illustrate the importance of the jingle as a sound brand, the voice-over and object sound might be substituted by similar types of sounds, e.g., from other contemporary commercials, without it having significant effect. The voice-quality of the voice-over is insignificant compared to the verbal semantic message, and the object sounds appear in an auditory background to the voice-over and jingle. The jingle, however, is not as easily substituted, and it appears co-textually privileged in an auditory foreground as the concluding expression.

In the following, I will examine how the sounds of the logo shot for Fakta compares to the rest of the 251 commercials in the sample presented above.

\section{Fakta compared to the sample}

The type of visual logo shot presented in the Fakta commercial - i.e., the logo presented explicitly in full screen during a few seconds at the end of the commercial - is quite typical of the commercials of the sample. However, as indicated in the beginning, variations from this tendency occur. Firstly, the logo shot may appear somewhere else during the commercial, e.g., at the very beginning or halfway. Secondly, the logo may be presented more implicitly as part of the presentation of a particular product or line of products, usually representing a so-called pack shot. Thirdly, the logo shot may constitute the whole commercial, which is usually encountered in the shortest commercials of the sample lasting 10 seconds (most of the commercials of the sample last 20-30 seconds).

\section{Speech}

Generally, speech is the most frequent type of sound in the sample. Thus, all commercials but three, i.e., three commercials for Stadium, include speech, and 233 out of the sample's 252 (approx. 92,5\%) logo shots include speech. Seen as a type of address of the viewer, speech may appear both indirectly and directly. The indirect address appears in the form of a dialogue between characters in a mini-drama, and usually the role of the product and brand is not spoken out explicitly. While indirect speech is generally not unusual in commercials, it is highly unusual during logo 
shots, where it might compromise the presentation and confirmation of brand elements and the sender of the commercial. At least, in the sample there is no dialogue during logo shots. The direct address can take the form of a presenter, a testimonial, or a voice-over (Stigel, 2001: 332ff.). The speech of the presenter and the testimonial are both visualized through appearances of a performing character, however, they differ in the way in which the speech is directed. The presenter has eye contact with the camera and is thus demanding something from the viewer, whereas the testimonial - e.g., a celebrity endorser - usually has eye contact with an imagined interviewer sitting behind the camera. Contrary to the visually immersed speech of the presenter and testimonial, the speech of the voice-over originates from 'outside' the visualized context. The three types of verbal direct address are all primarily factual in the sense that the speech is identifying and commenting on - i.e., providing information on - products, brands and services.

of the three direct types of address, the voice-over, as exemplified by the above commercial for Fakta, is by far the most frequent during the logo shots of the sample. However, contrary to the Fakta commercial, most voice-overs not only represent brand name and slogan, they also include, typically at the very end, a call-to-action, e.g., "See more on...", "Call us now on..." or "Come in our store...". The high proportion of commercials including a voice-over during the logo shot might be explained by the fact, that logo shots are intrinsically visual - i.e., they present the brand logo - so that the visualization of speech performing characters might attract too much attention and confuse this presentation. Also, persons are usually more transient than logos - e.g., people may be deceased, fired or hired by somebody else. To rely on a specific person during a logo shot is hence somewhat risky, while the use of persons is much more common during specific campaigns for particular, short-lived products or services. Exceptions for this tendency are the appearance of animated logos such as the Michelin Man or company managers such as Lars Larsen of JYSK, neither of whom appear during the logo shots of the sample.

The speech sounds of the logo shots in the sample bear a resemblance to the voice-over of the Fakta commercial. Hence, there is rarely anything distinctive about the voice quality apart from it being gendered. The gendered voice-over often seem to function stereotypically as an address of the target audience, i.e., female voices in commercials for women's magazine and male voices for most automobiles and tools. However, the genderedness of the voice does not represent a quality that distinguishes the advertised brand from other brands. Only in four cases does the quality of the voice-over distinguish itself from other commercials, as the voiceovers in various ways deviate from the above standard Danish (or English). Firstly, in a commercial for Ekstra Bladet, a celebrity voice appears in the form of the Danish former politician and current commentator, Hans Engell. Secondly, in a commercial for SEAT, a male voice-over airily whispers the brand name in synch with the 
showing of the logo. Thirdly, in a couple of commercials, distinct regional dialects appear, i.e., a swaggering Sealandic dialect in a commercial for Byggegarantifonden and a northern Jytlandic dialect in a commercial for Erling Christensen Møbler. Out of these commercials, I suggest that two represent sound brands, as the deviation from standard prosody is directly associated with the brand, and not a particular product - as is the case in the commercial with Hans Engell - or the depiction of an ironic character not associated with the brand or slogan, as is the case in the commercial for Byggegarantifonden.

In the commercial for SEAT, the whispering voice helps induce the brand of SEAT with passion and emotion. In doing so, it supplements other symbols of 'passion', such as the red colour of the visualized brand name, and the presentation of animated flames licking around the logo (see more below). In the commercial for Erling Christensen Møbler, the dialect helps address the target audience, e.g., 'one of us', and characterize the brand as something homely, trustworthy, and not too expensive.

\section{Music}

Next to speech, music is the most frequent type of sound throughout the sample. Thus, out of the sample's 252 commercials, 228 , i.e. approximately $90,5 \%$, include music. However, not all music during logo shots is foregrounded and distinct as the above musical brand of Fakta. In the following I will outline various ways in which music appears during logo shots in the sample. Since most logo shots include a voice-over, I commence by identifying ways in which the music relates to the voiceover. Two main types of relationships can be observed.

Firstly, the music will constitute an auditory background for the voice-over. The music here helps characterize the brand or product by inducing a particular mood or frame of mind. For example, an up-tempo rock beat structures the background for the voice-over in a commercial for the weekly magazine Se og Hør - indicating offers on, e.g., the latest news of the fashions of current celebrity (party)life - while a soft classical piano piece structures the background for the weekly magazine Familie Journalen - indicating offers on more restful topics, e.g., recipes and puzzles. The background music of the logo shot is often continued from the preceding parts of the commercial. In various ways, the music may indicate, that something else, i.e. the concluding voice-over at the end of the commercial, is about to commence. Thus, the music may slowly diminish as regards volume and/or density of musical impulses, hence functioning as an episode marker. Generally, background music does not attract attention to itself, and it functions as an auditory backdrop serving the presentation of the voice-over. Also, the music is typically rather indistinct in terms of its origin and its relation to its co-texts - e.g., it could be substituted by 
most other music displaying the same style indicators or displaced half a second without it having a significant effect.

Secondly, the music will 'interact' with the voice-over, as the music, e.g., a melodic or rhythmic motif, is auditorily foregrounded in combination with the voice-over during the logo shot. The above commercial for Fakta illustrates one such type of interaction, in which the music succeeds the voice-over (see commercials for Jem \& Fix and Jyllands Park ZOO for similar examples). In another example, a commercial for Fullrate, the music and voice-over is further interweaved as the music and voiceover presents a call-and-response-like structure that 'musicalizes' the slogan, i.e., "Simply low cost", in even eight notes and rounded curvature: "Simply" is succeed by an ascending melodic interval, while "Low cost" is succeeded by a descending melodic interval returning to the keynote that marks the end of the slogan as well as perhaps symbolically mirroring the 'low' cost. While these two examples illustrate how music and voice-over may appear and interact side by side, the music and voice-over might also interact synchronously. For example, a musical background from the first part of the commercial may clearly climax at the end of a commercial concurrent with the voice-over typically by way of a melody line (examples include commercials for Skousen, TDC, JYSK, McDonald's and Føtex). Hereby the music helps to lead in and orchestrate the voice-over as a kind of non-sung refrain or hook line of the commercial. This second type of music, which interacts with the voice-over during the logo shot, is distinct in that it cannot be substituted by other music of displaced half a second without it having a pronounced effect on the commercial message. Typically, this music functions as a musical brand, i.e., associated with the logo (and possible slogan) and used across commercials for a longer period of time.

As regards the logo shots with no voice-over, all of these include music, apart from the above commercial for Skoda. As this music will usually present a musical brand, the appearance of the music bear a resemblance to the music of the interactional' type. However, the exclusiveness of the music during the logo shot allows for certain variations.

Firstly, instrumental music might connect syntactically with the logo. Perhaps, as a result of having no relation to a voice-over, the music is centre staged and can appear exclusively as not only the sound of the logo shot but also, and more specifically, the sound of the logo. In cases where the logo is somehow animated, the sound of the logo can present itself as either 'emanating' from the animation - e.g., the music appears in synch with the animation of the logo of Intel, Sony and Renault - or as something to which the logo is 'dancing', perhaps even in synchrony to the musical impulses. For example, the animated cube, which functions as a logo for Danske Spil, is presented with a bumping roll toward the center of the screen, and each of the three bumps is synchronized with the three notes of the instrumental jingle. 
Secondly, the music may include a sung melody with lyrics. While a number of logo shots may include music that suggests lyrics, because of appearances of lyrics during the same melody line in previous commercials - e.g., in commercials for JYSK, Føtex and McDonald's - the appearances of musical lyrics during logo shots are rare. In one of the few examples, the brand name of Kokken og Jomfruen is presented during the logo shot through song. In another example, a commercial for Jyllands Park Zoo, a children's choir concludes the logo shot by singing "I børnenes paradise" whereby the target audience is both demonstrated and nominated.

Following a commonly held distinction (e.g., Tota, 2001), most musical brands are original, i.e., originating from the commercial in the sense that it has been produced for the commercial setting with no prior distribution (the above commercial for Fakta presents an example). A possible reason for this tendency is the fact that pre-existing music, i.e., music not produced for the commercial and with prior distribution and hence a pre-'existence', is hard to control. Similar to the above complications associated with the appearance of a celebrity voice, unknown and unforeseen past, present and future appearances could certainly compromise the brand value of a particular piece of pre-existing music. Exceptions from this tendency are represented in the sample by the use of Blicher's Jyden in a commercial for JYSK, Billy Paul's Your Song in a commercial for Star Tour Rejser, and Neil Richardson The Riviera Affair in a commercial for KIMs.

\section{Object sounds}

Object sounds may associate with the logo, the product or the brand. The Fakta commercial illustrates how the visual effects that present the logo (and slogan) are accompanied by object sounds. As indicated above, these object sounds are rather indistinct and throughout the sample this type of object sounds function as the "sounds of logo motion", e.g., the 'arrival', turning, putting, and bouncing of the logo, e.g., in commercials for Bilka and Vordingborg Køkkenet. While these motion sounds accentuates the presentation of the logo, they do not significantly characterize the logo or brand, as they are not foregrounded and not emblematic of the brand presented.

This also holds true of another widespread object sound, namely the sound of a clicking computer mouse. For example, in a commercial for Frisko, the logo shot ends with the mouse click-sound synchronized with a bouncing animation of the email address - as if the text is pressed upon - presented in close proximity to the logo. The animation here demonstrates the preceding voice-over's appeal to viewers to visit the website illustrating the above frequent call-to-action-function of voice-overs. 
The previously mentioned commercial for SEAT illustrates how object sounds in some commercials may help characterize the logo and brand. In this commercial, the whispering presentation of the brand name by the voice-over is accompanied by a low-pitched swaying sound, resembling the sound of a heavy sheet which is suddenly shaken. The sound is synchronized with the visual presentation of flames licking around the logo, and the object sound, apparently from flames, here adds significantly to the allusion of emotion and passion associated with the presentation of the logo. The sound of flames helps establish the sound brand of the whispering voice-over, but they do not function as sound brand in themselves, and they are not indexical of the products or service presented, i.e., SEAT cars and drivers do not sound like, or burst into, flames.

In addition to accompanying the animation of the logo, object sounds may also help characterize the brand name or product in various ways during the logo shot. For example, in a commercial for CBB mobil the sound of a waterfall accompanies the voice-over presenting the slogan: "tal som et vandfald" which translates to "run off at the mouth" or literally "talk like a waterfall". In a commercial for To Door, the sounds of a door bell help emphasize the brand name and service announced while sounds of construction, e.g., sounds of metal and wood being handled, synchronizes the sequential 'construction' of the logo of XL-Byg during the logo shot, hereby accentuating the companies offers on tools.

In a commercial for Dyson vacuum cleaners, the object sound corresponds directly to the product presented, i.e, the object of the object sound is the product. The commercial begins by loud suctions sounds of what is presented as the typical sound of ordinary, competing vacuum cleaners. As the voice-over identifies the brand name of Dyson, the suction sounds come to be associated with the presented Dyson vacuum cleaner. Following a decrescendo toward the end of the commercial, the logo shot is accompanied by very soft and vanishing suction sounds, while the voice-over stresses the lack of (annoying) sound when operating a Dyson vacuum cleaner.

The above examples illustrate how objects sounds may assist in presenting the logo, the brand name and slogan, as well as the product. Typically, in the sample, object sounds are not to be considered sound brands in and of themselves as they usually appear in the background of other sounds that may (or may not) represent the brand sound, see for example the music of the Fakta commercial and the voiceover of the SEAT commercial. Analogous to the appearances of celebrity voices and pre-existing music, the spread of object sounds outside the setting of the commercial makes it difficult to 'monopolize' or 'colonize' the signifying potential of object sounds. However, on two occasions in the sample, an object sound presents a sound brand, i.e., the chiming bells of Hjemis and the sound of a cash register in a commercial for Netto. Both object sounds accompany the logo without other concurrent 
sounds, and they contribute significantly in characterizing the brand. The chiming bells are indexical of the service of Hjemis, as the bells, heard outside the setting of the commercial, signals the arrival of the delivery truck on streets with private houses. Hence, the object sound is pivotal to the brand and service of Hjemis. The sound of the cash register is not indexical of Netto, as the sound is not normally heard in a Netto store and the sound is in fact anachronistic compared to the sound of present day registers. However, as the sound represents a stylized stereotype of a cash register and, hence, money transfer, the object sound helps brand Netto as competitive as regards prices and costs. Compared to the above commercial of Fakta representing a similar brand position, the singular object sound - in combination with the simple, non-animated logo presentation in general - indicates that the costs and service of Netto are even more 'cut to the bone'. Moreover, as it signals the conclusion of a transaction, perhaps the object sound helps suggest, that the viewer has 'cut a deal' with Netto while watching the commercial, i.e., the viewer is 'rewarded' for having seen the commercial and is finally 'certified' to shop in Netto.

\section{Sound brands}

Following from the above analysis of the three main types of sound in the sample, it is now possible to provide an indication of the prevalence of sound brands. Certainly, given the nature of the sample at hand, the examination cannot assess sound brands from otherwise important perspectives of sound branding, i.e., whether a particular sound brand can be tracked over a longer period of time in relation to the same brand, and whether the sound brand is used in similar ways across different media settings and campaigns. However, tendencies can be observed from the perspective of distinctness, i.e., whether the use of sound differs from uses of sound in other commercials, and whether the use of sound adds pointedly to the syntax and semantics of the commercial. Commutation tests (see Hjelmslev 1943, Tagg \& Clarida, 2003, and Graakjær 2011) offer a simple, yet instructive way to indicate whether a use of sound is distinct. For example, an indication of the pertinence of the sound can be indicated by substituting or rearranging (the placement of) the sound, as exemplified above.

On these premises, while only one logo shot is devoid of sound, 76 commercials of the sample's 252 commercials, i.e. approximate $30 \%$, includes a sound brand (see table 2). Some of these have been exemplified above, and the tendency is clear: Music is the most prevalent type of sound brand - i.e., 72 commercials include a musical sound brand - whereas object sound and voice-over sound brands are each represented by two commercials. 
Table 2. Distribution of sound (brands) during logo shots from a sample of 252 commercials

No sound Non-brand sound $\quad$ Sound brand

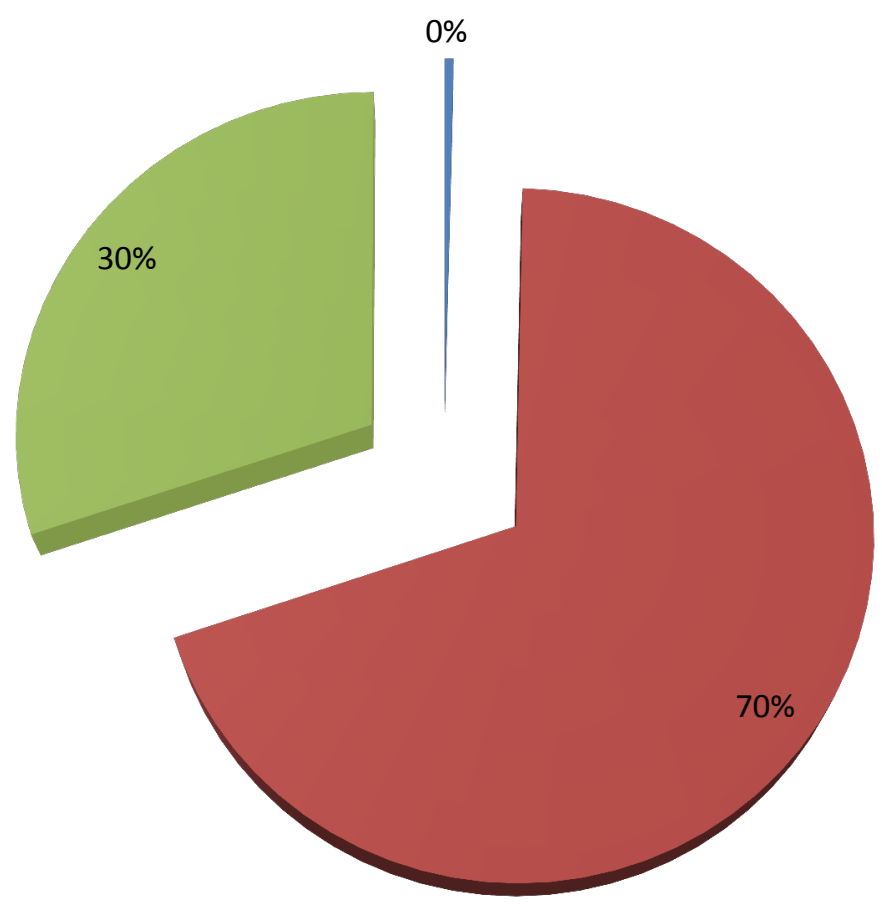

Because very few studies of comparable samples exist, these findings cannot be straightforwardly further qualified, e.g., as regards whether the distribution of sound brands is remarkable high (or low) or has changed. However, in light of the prevalence of visual brands and the importance of sound in television commercials - e.g., sound can function as an 'umbilical cord' for visually distracted viewers - it may be argued that the frequency of commercials with sound brands is rather low. At any rate, additional research, e.g. examination of larger samples of commercials, is needed to further examine the prevalence of sound brands in television commercials.

\section{Conclusion}

In this article, I have illustrated how a textual analysis of sound and its audiovisual setting can offer relevant and necessary insights into processes of signification during a logo shot. In doing so, I have presented a typology of sounds, which has been illustrated by the Fakta case and further nuanced through an analysis of a sample. This analysis has made contribution to the understanding of sound brand- 
ing, specifically by providing an indication of possible types and prevalence of particular sound brands.

In summing up, table 3 provides an overview of some of the most significant analytical perspectives, which have been demonstrated during the preceding analysis. The table indicates how the three types of sound can be analyzed from three supplementary perspectives, i.e., the sound and its relation to sounds from outside the setting of the commercial, the relation between sounds, and the relation between sounds and visuals.

Table 3. Overview of types of sounds and analytical perspectives

\begin{tabular}{|c|c|c|c|}
\hline Type of sound & Music & Speech & Object sound \\
\hline The sound & $\begin{array}{l}\text { * Origin (pre-existing } \\
\text { or original) } \\
\text { * Format (e.g., in- } \\
\text { strumental or sung, } \\
\text { background) }\end{array}$ & $\begin{array}{l}\text { * Origin (a celebrity } \\
\text { voice or not) } \\
\text { * Dialect } \\
\text { * Genderedness }\end{array}$ & $\begin{array}{l}\text { * Origin (relation to } \\
\text { sounds of objects } \\
\text { known from outside } \\
\text { the commercial) }\end{array}$ \\
\hline $\begin{array}{l}\text { The relation } \\
\text { between } \\
\text { sounds }\end{array}$ & \multicolumn{3}{|c|}{$\begin{array}{l}\text { * 'Horizontal' perspective (e.g., the sequential 'interaction' between } \\
\text { sounds) } \\
\text { * 'Vertical' perspective (e.g., the layering of sounds appearing in the } \\
\text { background or the foreground) }\end{array}$} \\
\hline $\begin{array}{l}\text { The relation } \\
\text { between } \\
\text { sounds and } \\
\text { the visuals }\end{array}$ & $\begin{array}{l}{ }^{*} \text { Musicalization of the } \\
\text { logo presentation }\end{array}$ & $\begin{array}{l}{ }^{*} \text { Mode of address } \\
\text { (direct or indirect) }\end{array}$ & $\begin{array}{l}\text { * Product sound } \\
\text { * Logo sound } \\
\text { * Slogan sound }\end{array}$ \\
\hline
\end{tabular}

The table might serve as an inspiration for further studies of sounds during logo shots. Whereas the specific dimensions included are of course not exhaustive - for example, the category of music can be examined in additional detail when it comes to, e.g., the music's style, genre and format as well as the functions of the music in its relation to the visuals - the table can be seen as an analytical framework including three levels of text analytical perspectives. I suggest that these perspectives are necessary towards an understanding of the signifying potentials of sounds during logo shot, hereunder possible sound brands. From the perspective of this framework, sound brands can be identified when the sound in question is 1) distinct from other sounds in other commercials (regarding 'the sound'), 2) auditorily foregrounded (regarding 'the relation between sounds'), and 3) appears in detailed synch with the presentation of the logo/slogan (regarding 'the relation between the sounds and the visuals'). The framework hence highlights the importance of examining not only sounds, but also relations between sounds and visuals, and this insight arguably adds a crucial dimension to the understanding of corporate sound brands. 


\section{References}

Allan, D. (2008). A Content Analysis of Music Placement in Prime-time Television Advertising. Journal of Advertising Research, 48(3) 1-14.

Anzenbacher, C. (2012). Audiologos. Integrative Gestaltungsmaßnahmen vor dem Hintergrund der Musikpsychologie. Nomos: Baden-Baden.

Augoyard, J-F. \& Torgue, H. (2006). Sonic experience. A guide to everyday sounds. McGill-Queen's University Press: Montreal.

Bonde, A. \& Bang. K. (2012). Musikalske lydlogoers DNA. Akademisk Kvarter, Special Issue: Student's minutes. P. 210-230.

Bronner, K. \& Hirt, R. (2009). Audio Branding: Brands, Sound and Communication. Nomos/Reinhard Fischer: Baden-Baden.

Graakjær, N.J. (2009). Music in TV commercials - Formats, frequencies and tendencies. In N.J. Graakjær \& Chr. Jantzen (red.), Music in advertising - Commercial sounds in media communication and other settings. Aalborg: Aalborg University Press. P. 53-73.

Graakjær, N.J. (2011). Musik i tv-reklamer - Teori og analyse. København: Samfundslitteratur.

Graakjær, N.J. \& Bonde, A. (2013). Lydbranding - En database over litteraturen [Sound branding - a database of the literature] Videnskab.dk. 23 May. http://videnskab.dk/blog/lydbranding-endatabase-over-litteraturen-pa-omradet.

Groves, J. 2011. Commusication. From Pavlov's Dog to Sound Branding (Cork: Oak Tree Press).

Hjelmslev, L. (1943). Omkring sprogteoriens grundloggelse. København: Københavns Universitet.

Høier (2010). Lyden av mediering - En utforsking av nyere sjangertrekk innenfor filmtrailere [The sound of mediation - Exploring new aspects of the movie trailer genre]. MedieKultur, 48, p. 104114.

Jackson, D. (2003). Sonic Branding: An Introduction. Palgrave Macmillan: London.

Jackson, D. (2006). Orchestrating a sound strategy. Brand Strategy, 199, pp. 38-40.

Leeuwen, Th. van (1999). Speech, music, sound. Hampshire: Palgrave Macmillan.

Lucensky, J. (2011). Sounds like banding: Use the power of music to turn customers into fans. A \& C Black Publishers Ltd.

Mey, J. (1993). Pragmatics. An introduction. Oxford: Blackwell.

Morris, C. (1946). Signs, language and behavior. Prentice Hall: New York.

Palghat, V.K., 2009. Hearing, Remembering, and Branding: Guidelines for Creating Sonic Logos. Ph.D. University of Cincinnati.

Riggins, N., 2007. Sound's Function in the Branding Process. MA. University of Kansas.

Schafer, R.M. (1977). The tuning of the world. New York: Random House.

Stigel, J. (2001). 'The aesthetics of Danish tv-spot-commercials. A study of Danish TV commercials in the 1990'ies' in F. Hansen \& L.Y. Hansen (eds) Advertising Research in the Nordic Countries, pp. 327-350. København: Samfundslitteratur.

Tagg, P., \& Clarida, B. 2003. Ten Little Title Tunes (New York: MMMSP).

Tota, A.L. (2001). '"When Orff meets Guinness": Music in advertising as a form of cultural hybrid, Poetics, 29, p. 109-123.

Traux, B. (2001). Acoustic Communication (2. Ed.). Westport: Ablex Publishing.

Treasure, J. (2007). Sound Business - How to use sound to grow profits and brand value. Gloucestershire: Management books.

Venkataraman, Arun (2007). The sonic boom: Effect of logo presentation style in television commercials on memory for the advertised brand. Columbia, MA: University of Missouri.

Vroomen J, \& de Gelder B. (2000). Sound enhances visual perception: cross-modal effects of auditory organization on vision. Journal of Experimental Psychology: Human Perception and Performance, 26(5), p. 1583-90. 